\title{
Community Building: An Integrated Approach to Horseshoe Crab Conservation
}

\author{
Glenn Gauvry \\ Ecological Research \& Development Group Inc., Dover, DE. USA
}

\begin{abstract}
Throughout the world, many marine species that come to shore to breed face increased risks from human activity, ranging from coastal development, pollution, and human-induced erosion to the harvesting of individual animals at a time when they are most vulnerable.
\end{abstract}

The regulatory process can mitigate a portion of this risk, but it is difficult to regulate human behavior, particularly when those being regulated are not in agreement over the necessity of such regulations and when such regulations are perceived to interfere with economic growth or individuals' livelihoods. In addition, the regulatory process often alienates the very communities that are most able to assist in the stewardship of the natural resource.

From its inception in 1995, the Ecological Research \& Development Group (ERDG) has recognized the importance of building an engaged community to achieve wildlife conservation. An engaged community, if given the chance, will far surpass the unimaginative "conservation through regulation" approach. An engaged community is more aware of the changes in the environment; is in the best position to educate neighbors and visitors; and is more likely to assist stranded or injured animals, help with scientific analysis, shape public opinion, and report infractions of regulatory statutes.

This paper describes the tools and strategies ERDG has developed to promote the conservation of the world's four horseshoe crab species at a community level. These tools can be adapted to other situations around the world to help to develop community-based conservation initiatives that engender a spirit of cooperation and inclusion.

\section{Introduction}

The world's four horseshoe crab species, with few exceptions, do not spawn within protected habitats. They come ashore where humans live, play, and work. Sometimes they are accepted, but more often they are exploited or even reviled; numerous horseshoe crabs die from stranding on beaches during the spawning season each year, and their carcasses create an odorous and untidy shoreline, often in areas where the value of luxury homes and vacation destinations depend on a "pristine" environment.

It is here; within these coastal communities, that horseshoe crab conservation can be most effective. Driven by science as well as economic considerations and strengthened by compassion for both the natural resource and the community, a conservation framework can be established. 
Building on the belief that conservation is an informed individual's responsibility, which establishes the foundation for community-based conservation, the Ecological Research \& Development Group (ERDG), a 501 (c) (3) nonprofit organization, created The Horseshoe Crab Conservation Network ${ }^{\mathrm{TM}}$. This paper outlines the network's multifaceted, cross-cultural initiatives designed to inform and engage individuals and organizations in the conservation of the world's four horseshoe crab species.

ERDG's Web site, www.horseshoecrab.org, forms the network's core, providing information about horseshoe crab species to hundreds of thousands of visitors annually. ERDG's exhibits and classroom tools reach thousands more. The power of expression from our young environmental stewards is vastly underutilized. ERDG's Young Voices, Horseshoe Crabs and the Arts ${ }^{\mathrm{TM}}$ program unites these voices throughout the world.

ERDG's Just flip 'em!@ program was designed to bring attention to the thousands of spawning horseshoe crabs that die each year from being stranded upside down. ERDG's Practical Conservation program has been responsible for a substantial reduction in the use of horseshoe crabs as bait in the U.S. conch fishery.

ERDG's horseshoe crab sanctuary program encourages coastal communities to declare their shared habitat a horseshoe crab sanctuary and promote species awareness to visitors and neighboring communities. To support community-based horseshoe crab conservation initiatives around the world, ERDG created The Horseshoe Crab Conservation Fund ${ }^{\mathrm{TM}}$.

\section{The Programs}

"Never doubt that a small group of thoughtful, committed citizens can change the world. Indeed, it is the only thing that ever has." Margaret Mead (Warner 1992)

Although fascination and admiration of a species may not form the base for good science or resource management, it is the primary motivator of community-based conservation. ERDG developed The Horseshoe Crab Conservation Network ${ }^{\mathrm{TM}}$ to spark admiration and fascination of the horseshoe crab and build community concern and conservation efforts for the species.

The Horseshoe Crab Conservation Network ${ }^{\mathrm{TM}}$ is a multifaceted, cross-cultural suite of seven integrated initiatives designed to inform and engage the broadest coalition of individuals, communities, organizations, and scientists in the conservation of the world's four horseshoe crab species.

\section{Education and Outreach: Reaching Students, Communities, and Researchers on the World Wide Web}

The power of the Internet to move information around the world is unequaled. Through ERDG's award-winning Web site (www.horseshoecrab.org), information and educational tools are placed in the hands of individuals, communities, and organizations who are actively engaged in the 
science and conservation of horseshoe crabs. The success of ERDG's site is measurable: in 2007, it had over 350,000 visitors and was linked to 1,500 other Web sites (Google 2007).

Topics addressed on the site include evolution, natural history, anatomy, medical uses, research, conservation, global distribution, and news. A special section of poems, tales $\&$ images is also featured. ERDG's goal is to provide the world with the most comprehensive source of peerreviewed information on the world's four horseshoe crab species.

The Web site also provides a platform for community interaction and cultural exchange. To further facilitate the exchange of information and ideas, ERDG is working to make the site multilingual. Although this will take some time, the growing support from ERDG's international partners makes this task more manageable.

A comprehensive Web site that offers tools to educators, students, and researchers can be a critical step to raising awareness and involvement, even when the individual citizens in a community of concern do not have access to the Internet themselves. A number of species (Bengal tigers, mountain gorillas) have local conservation groups committed to their protection, but worldwide attention for these species has been raised through the media, including the Internet, creating a global community effort for their conservation.

\section{Expanding Beyond the Internet - Tools for Education}

Although ERDG believes in the power of the Internet to move information around the world, information alone will only engage the most committed student. To reach the broadest possible audience, it is important to transform this information into compelling learning tools. To that end, ERDG has assisted in the development of interpretive centers and has designed exhibits, signage, and printed information. The world's only life-size teaching model that reveals the horseshoe crab's internal anatomy was designed by ERDG. These museum-grade models are used by schools, nature centers, and aquariums throughout the United States and Japan.

The DuPont Nature Center at the Mispillion Reserve, located at the north end of Slaughter Beach, Delaware, is situated on one of the most prolific horseshoe crab spawning beaches and migratory shorebird stops in the world. Thousands of visitors annually will learn about horseshoe crabs and shorebirds from the centers information. In addition to providing information content for the center's exhibits, ERDG assisted in the centers design and development.

ERDG continues to explore opportunities to transform its Web-based information and conservation message into compelling learning tools for all ages. Education through nonelectronic means, such as public programs, can be tailored to any age group.

\section{Young Voices ${ }^{\mathrm{TM}}$, Horseshoe Crabs and the Arts}

It is important, as focus is placed on the science of this remarkable mariner, that we do not lose sight of our compassion for these living beings, for it is compassion that lies at the heart of 
conservation. Young Voices is a program designed to explore, express, and nurture the compassionate heart. The power of expression from our young environmental stewards is a vastly underutilized resource.

Through ERDG's in-school program, annual juried art competition, traveling art exhibition, and Web-based digital art gallery, these voices are united throughout the world in celebration of the horseshoe crab. ERDG's in-school program uses the science of horseshoe crabs as a means to evoke artistic expression, creating a bridge to the annual juried art competition. Thousands of students have contributed to this collective voice, sharing their heartfelt expression through poems, stories, images and musical compositions.

ERDG is presently developing online lesson plans to help teachers to replicate this program in areas beyond the reach of ERDG's staff. Through ERDG's traveling art exhibition and digital art gallery, these Young Voices and the conservation message that lies within them can be heard around the world.

\section{Practical Conservation: Reducing Human Impact and Engaging the Broadest Coalitions}

This initiative is designed to build conservation partners, not enemies, out of conflicting user groups. ERDG seeks common ground and innovative solutions to reduce the detrimental effects of human activity on the world's four horseshoe crab species. This is accomplished by creating an interface between the various interest groups and the science and technology associated with the issue at hand.

It is essential to the success of any conservation plan that the concerns of the community regarding its role as a conservation partner be addressed. These concerns can be as simple as providing community-wide education and assisting in the development of conservation plans, land use issues, logistics, etc. or as complex as finding economic incentives and/or solutions to address the loss of income to communities that may depend on the resource for all or part of their livelihood.

ERDG was responsible for initiating the first study to test the effectiveness of bait bags in reducing demand on horseshoe crabs as bait in the U.S. conch fishery (ASMFC 1999). Working with the Virginia Institute of Marine Science (VIMS), it was shown that bait needs could be reduced by half if placed in a bait bag (Fisher and Fisher 2000). To promote this initiative, ERDG manufactured and distributed, free of cost, over 15,000 bait bags to conch fishermen along the Atlantic Coast of the United States (Germano 2003). In addition, ERDG is actively facilitating dialog between various interest groups towards the development of alternative bait.

In 2004, ERDG organized an alternative bait and gear workshop, which was held in Baltimore, Maryland and sponsored by the Atlantic States Marine Fisheries Commission (ASMFC). The purpose of the 2-day meeting was to bring together watermen, fisheries managers, researchers, distributors, and Limulus amebocyte lysate (LAL) manufactures from up and down the Atlantic Coast to share ideas, designs, and strategies that would reduce the need for horseshoe crabs in the 
conch and eel fishery. The net result of the meeting was an outline containing many sound ideas in terms of gear and bait alternatives that, if financed, could lessen the pressure on the horseshoe crab resource without the need for additional regulatory restrictions (ASMFC 2004).

Although it is easy for people to take sides in any conservation issue, it is far more effective and productive if all sides can work together to find ways to solve a problem. It requires more time, effort, and innovation, but in the end, it helps to build a cooperative community of problemsolvers who will readily accept the solutions they themselves have had a hand in creating.

\section{Backyard Stewardship ${ }^{\mathrm{TM}}$ : Coastal Communities Define Their Shared Habitat as a Horseshoe Crab Sanctuary}

The future survival of the world's four horseshoe crab species will ultimately depend upon the preservation of spawning habitat; a challenging prospect in light of the ever-increasing human density along the same beaches horseshoe crabs rely on for propagation. ERDG's communitybased sanctuary program was designed to encourage coastal communities around the world to declare their shared habitat a horseshoe crab sanctuary and promote awareness of the species to visitors and neighboring communities.

Since the program's inception in 1998, ERDG has discovered that regardless of what initially motivates a community to become a horseshoe crab sanctuary, as they begin to embrace this idea of a shared habitat, a paradigm shift occurs. It begins on an individual level, as residents become educators to their friends and neighbors who visit them, and while they walk along the beach and come in contact with this remarkable animal. Eventually, the community as a whole begins to embrace the idea that they are stewards of their environment and this is one species that should be included in that stewardship.

Compassion for all living beings lies at the heart of ERDG's conservation philosophy. Backyard Stewardship is a continuation of the process begun with Young Voices. Both are designed to explore, express, and nurture the compassionate heart. As of 2007, six (6) Delaware communities are participating in ERDG's horseshoe crab sanctuary program; they include Broadkill Beach, Prime Hook Beach, Fowler Beach, Slaughter Beach, Kitts Hummock, and Pickering Beach. To date, ERDG's community-based horseshoe crab sanctuary program has protected over 15 miles of some of the most productive horseshoe crab spawning beaches in the world. In addition, ERDG has just finished a documentary designed to help coastal communities establish horseshoe crab sanctuaries in the state of New Jersey. Ultimately, ERDG plans to expand this documentary to assist coastal communities throughout the spawning range of horseshoe crabs worldwide.

Any community can decide that it wants to protect habitat for one or more target species; all it takes is one person or group to be the first. In some areas, an economic benefit must be shown before a community agrees that a habitat is worth saving, but the recent boom in ecotourism is proof that many habitats have enormous value. 


\section{Just Flip 'em! ${ }^{\circledR}$}

This program is designed to bring attention to the hundreds of thousands of horseshoe crabs (Limulus polyphemus) that die each year from stranding (stuck upside down) during their yearly spawning ritual. It encourages individuals, through a simple act of compassion, to take the time to assist and appreciate these remarkable creatures, which will not survive public indifference.

Studies have shown that as much as $10 \%$ of the spawning horseshoe crab population dies each year from being stranded upside down during spawning (Botton and Loveland 1989). The success of this program is a measure of how effectively it engages individuals and communities behind the conservation of their shared resource.

Sometimes, all it takes is one simple action to make a difference, and if one person can do it instead of walking by with a blind eye, then others will also see that they can do it, too.

\section{The Horseshoe Crab Conservation Fund ${ }^{\mathrm{TM}}$}

To build upon the success of the horseshoe crab sanctuary program and to find a vehicle to expand the program beyond ERDG's physical reach, ERDG created the Horseshoe Crab Conservation Fund ${ }^{\mathrm{TM}}$, which is an endowment fund designed to support community-based horseshoe crab conservation initiatives around the world. Through partnership with the scientific community, The Horseshoe Crab Conservation Network ${ }^{\mathrm{TM}}$ has the potential to inspire and assist individuals, communities, and organizations to solve problems, change behaviors, and promote sound decisions in the conservation of the species. Although the fund is operational, its financial resources are small. Currently, ERDG is using the funds to assist communities who have declared themselves horseshoe crab sanctuaries in creating interpretive signs and educational materials and in developing plans to protect the community's natural resources. Ultimately, several mini-grants each year will be awarded to communities around the world who are engaged in the conservation of their horseshoe crab species.

While fundraising can be one of the most difficult challenges for any organization, even small amounts of money used for community education can have an enormous impact.

\section{Summary}

Throughout the world, marine species that come to or near the shore to breed, be they horseshoe crabs, sea turtles, seals, fish, or pelagic birds, are at an increased risk from human activity. Many of these species suffer simply from the lack of awareness borne from ignorance, indifference, and/or intolerance. Their survival has yet to be elevated to a level of concern, much less a level of regulation. In many parts of the world, the human struggle for survival, which is often dependant on these species, overshadow conservation concerns. For these animals, communitybased conservation efforts represent their best hope for continued existence. 
In community building, the key to success is advocacy from within the community. One respected and committed individual is all that is required to build a movement. It is not necessary to begin with the community most strategically placed in relationship to the natural resource, for as the movement grows, it will eventually encompass neighboring communities and, eventually, the full range of the habitat.

There is a considerable amount of detail associated with The Horseshoe Crab Conservation Network ${ }^{\mathrm{TM}}$ that cannot be explored in the body of this document. However, it is a growing and viable network with the capability of serving the global community committed to the science and conservation of the horseshoe crab. Although specifically designed to promote the conservation of the world's four horseshoe crab species, we believe these tools and strategies can be tailored to other species and communities around the world where humans and wildlife share the same habitat, particularly- as in the case of the horseshoe crab- species that lack the visual aesthetics and behaviors to awaken the compassion of their potential stewards.

\section{References}

ASMFC (1999) [cited 2008 Feb 10]. Minutes of Alternative bait and trap design workshop for horseshoe crabs. Available from: http://www.horseshoecrab.org/news/media/altbaitwkshop.pdf

ASMFC, ERDG (2004) [cited 2008 Feb 10]. Summary of conch bait and gear workshop. Available from: http://www.horseshoecrab.org/news/pdf/Bait\%20Workshop\%20Summary.pdf

Botton M, Loveland R (1989). Reproductive risk: high mortality associated with spawning by horseshoe crabs (Limulus polyphemus) in Delaware Bay, USA. Marine Biology 101: 143-151.

Ecological Research \& Development Group Inc. [homepage on the Internet] [updated 2008 Feb 10; cited 2008 Feb 10]. Available from: http://www.horseshoecrab.org/.

Fisher R, Fisher D (2000). The use of bait bags to reduce the need for horseshoe crab as bait in the Virginia whelk fishery. VIMS Marine Resource Report No. 2006-10. Also available from: http://www.vims.edu/adv/fisheries/MRR2006_10.pdf

Germano F (2003). Horseshoe Crabs, Balanced management plan yields fishery and biomedical benefits. DMF News, vol. 23 (second quarter): 7. Also available from:

http:/www.mass.gov/dfwele/dmf/publications/dmfnq203.pdf

Google Business Solutions (2007). Available from: www.bizsolutions.google.com/services

Warner C (ed.) (1992). Treasury of Women's Quotations. Paramus: Prentice Hall. 